\title{
Virtual Mobility: The Lived Experience of Exchange Students in a Higher Education Institution in Asia
}

\author{
Annabelle B. Francisco ${ }^{1}$ \\ ${ }^{1}$ Ilocos Sur Polytechnic State College, Sta. Maria Ilocos Sur, Philippines \\ *bellefrancisco@ispsc.edu.ph
}

\begin{abstract}
The COVID-19 Pandemic has paralyzed the internationalization efforts of higher education institutions worldwide by hindering the physical mobility of the students, yet, the Ilocos Sur Polytechnic State College in the Philippines found a way to take the challenge an opportunity instead to internationalize through the use of emerging information and communication technologies. It is during this time, that the College launched its first-ever International Credit Transfer Program with its Indonesian University partner virtually. With this new dimension of student mobility, the researcher can't help but reflect on these questions: what do students bring home from their virtual student exchange experience? how educational and transformative are their virtual experiences to say that the mobility is not just like their other local/regular online classes? Using phenomenology both as a philosophy and a methodology, this work provides a thick description of the lived experiences of 16 Education major students captured through in-depth interviews and analysis of their journal entries. Five themes illuminated: Enhancing Macro skills; Reducing Affective Filters; Igniting Patriotism; Acquiring Digital Literary; Instilling 21st Century Skills. Findings reveal that the virtual experience brought new scholarships to the participants. The use of the online platforms was not at all deemed as a hindrance by these students rather they believe the platforms channeled them to have the 21st Century skills of Educators. Policy recommendations to better and sustain the program are included too, in this paper.
\end{abstract}

Keywords: virtual mobility, online student exchange, phenomenology

\section{INTRODUCTION}

The mobility of students to study overseas is an increasing phenomenon in higher education institutions globally [1];[2];[3]. Internationalization through international student mobility has reshaped teaching and learning in higher education by providing varied rewards not only to the students but also to the institutions, communities, and countries as well [3]. While international student mobility brings benefits, it also constructs other sets of yardsticks for higher education institutions (Rizvi, 2006 in [4], where Universities are challenged to produce globally competent graduates who are preferred in the global market for employment [4]. With this challenge dispatched to higher education institutions, administrators have to revisit, review, and revise their respective curricula following the standards set at the international level where there are an integration of transnational, intercultural, relative lenses to pedagogy, content, and student learning outcomes [3].
The COVID-19 Pandemic has paralyzed during the early months of its desolation the internationalization efforts of not just Philippine higher education institutions but HEIs worldwide by hindering the physical mobility of the students, yet, the Ilocos Sur Polytechnic State College located in North Luzon Philippines found a way to take the challenge of the Pandemic an opportunity instead to internationalize through the use of emerging information and communication technologies (ICTs). During the Pandemic, classes in ISPSC have shifted to blended, flexible learning. However, it is not only its regular classes migrating from the traditional face-to-face classes to the online platform, rather it launched its firstever International Credit Transfer Program with an Indonesian University virtually.

With the absence of face-to-face instruction and with the utilization of emerging information and communication technologies for teaching and learning, the researcher can't help but reflect on these preliminary questions: What do students bring home from their 
virtual student exchange experience? How educational and transformative are their experiences to say that the virtual mobility is not just like their other local/regular online classes?

The researcher, hence, find the necessity to study this complex phenomenon by attempting to describe and understand the lived experiences of the virtual exchange students in a higher education institution in Ilocos Sur, Philippines

\section{METHOD}

This study used Phenomenology to gain an understanding of the lived experiences of the virtually exchanged students as they attended classes in an Indonesian University online.

In this study, 16 students from the College of Teacher Education from Sta. Maria and Tagudin campuses respectively served as participants of the study. The students were a mixture of Elementary/Primary and Secondary major students. They were chosen to participate in the one-semester International Credit Transfer Program commencing from March 2021 to July 2021 which was an offshoot of the partnership of Ilocos Sur Polytechnic State College, Philippines, and its partner university in Indonesia. This is the first time that the former sent its students for an international program.

Two data gathering vehicles were used: journal entries and in-depth interviews. The 16 studentparticipants submitted their portfolios which contained their journal entries. The students were informed that their journal entries will be one of the sources of data for this study.

To validate and add more depth to the data digested from the journal entries, the researcher conducted indepth interviews. Here, ten (10) were randomly selected from the sixteen students. The interview was scheduled at a time and platform convenient to the participants. Before the start of the interview, the researcher informed the participants that the interview was audiorecorded and will be transcribed. The information they revealed will be kept confidential and that their names will not be mentioned in the submitted output. The researcher also asked the participants if they would be comfortable with "English" as the medium of communication during the interview. The interview question the researcher asked: How will you describe your experience as exchange students who were sent by ISPSC not in person to the host University but just virtually? The interview was sound recorded and transcribed verbatim. The researcher transcribed the sound recording right after the interview. The researcher used open coding as a tool to sort, retrieve, link, and display data and categorization[11] by identifying a chunk or unit of data (Spiggle, 1994 as cited in [11] from the transcription which led to the creation of themes.

Thematic analysis and determination of themes were done both for journal entries and in-depth interviews to grab the essence of the phenomenon and answer the research questions.

\section{RESULTS AND DISCUSSION}

Five themes emerged: Enhancing the four macro skills which describe how speaking, reading, writing, and listening skills of the participants were enhanced by their participation in the program; Reducing affective filters capsulizes the experiences of the participants on how the affective filters shrank as they went through their day to day lives as virtual exchange students; Igniting patriotism are the reflections of the participants on how their exposure to the international platform revived their pride as Filipinos and love for their country; Acquiring digital literacy reflects the narratives of the students on their exposure and use of the online platforms as the main channel for the teaching and learning process in the virtual student exchange; Instilling the 21st-century skills echoes the life-long learning skills or competencies acquired and instilled among the students during and after their participation to the International Credit Transfer Program.

The following results and discussions are arranged based on the emerging themes which transpired from the journal entries and in-depth interviews.

Theme 1: Enhancing the Four Macro Skills

The experiences of the Filipino virtual exchange students coincide with the experiences of other students who also had experienced using ICT such as a social network as supplemental platforms in their English classes where they affirmed that their English macro skills improved [12];[15]. The use of English as the medium of instruction and interaction in the virtual classes manifested through the teachers' use of various activities agree with findings of [16] that classes that are activity-based and collaborative with teachers administering varied activities ranging from class activities, paired works, individual or group activities enhance the four macro skills of the students.

Theorizing from the results, the shift of the platform from the old supplemental role of the online platform to it being the main platform today because of the Pandemic as a venue for teaching and learning process is not seen as a hindrance of the students rather they looked at the present context as opportunities to explore possibilities of improving their skills especially to the commonly neglected skills during the old normal teaching and learning such as reading and writing. The students felt as if they were physically present in Indonesia. This means that even though the classes were 
done virtually, the platform was a channel that brought the students to Indonesia. The meaningful experiences carried by the various activities provided by the teachers with English as the main medium of communication were present and were brought home by the students. The following are the direct statements from the participants:

"I improved my reading comprehension skills because of the .pdfs sent that I have to digest. This also improved my vocabulary which helped me in my writing submissions" PC

"Most activities are given required reading and writing which for me required a lot of independence and this freedom helped me explore on my own making my writing not restricted.” $\mathrm{PJ}$

"My communication skills improve through the use of the English language in the classroom interactions and activities/tasks". PL

"During the synchronous classes, I have to listen attentively so that I won't miss the important words from the discussion and this I think enhanced my listening skills which were my waterloo." PE

\section{Theme 2: Reducing Affective Filters}

The use of ICT in virtual mobility helped eased the anxieties of the student participants for they were able to collaborate, work with a team with active involvement, share information and resources, and employ critical thinking [17] between and among their classmates and faculty. The experience of the student participants affirms with [18], [19] that social networks build a virtual communal space where students can establish and maintain relationships with their fellow students and teachers as well. Online social interaction may be caused by the intention to connect with new acquaintances, impart thoughts, and share pieces of information [20]. The virtual mobility reduced the affective filters such as shyness, lack of self-confidence, unsupportive learning environment, and stiff competition usually found in the old normal classroom teaching and learning. The new space provided a healthy environment where the learners were able to freely express themselves without anxiety. Despite being held virtually, the classes were found conducive and convenient for learning by the participants. This means that virtual mobility offers borderless education but leaves a distinct emotional imprint that facilitates the acquisition of learning especially the second language.

"I am not a sociable person but when I enter this new world I am now able to develop my skills in communicating with other people. This program helps me to adapt to a new environment and share in a diverse classroom where this could help me soon in educating my learners with different races, cultures, and languages." PN

"The use of the online platform has seemingly reduced my shyness especially in expressing myself during recitations. It felt like I have more freedom to speak what's on my mind. " PO

"I was more confident in speaking when we have our online classes than when I was meeting my classmates and teachers face to face." PD

"The very affirming culture, helpful and friendly environment, and classmates and teachers helped me in coming out of my shell and rediscover myself and have a better version of myself after undergoing the program." $\mathrm{PP}$

"We developed friendship rather than the competition so the classes were just light and enjoyable although the requirements were heavy." PL

Theme 3: Igniting Patriotism

The experience the students divulged affirm the contention of [22] when they posited that student participants in the international mobility program experienced alterations of their sense of individuality and ethnicity and their sensitivity of others' culture, beliefs, norms, practices, and approaches. Consciously and unconsciously they compared and contrasted their cultural practices and attitudes to and from their counterparts. These reflections rekindled their being Filipinos and drove them further to appreciate where they came from and who they are as Filipinos. They also carried with their pride and joy as they performed well in that particular arena because they were not only performing as students but as Filipinos.

"This program helped me to adapt to a new environment and share in a diverse classroom with different races, cultures, and languages. This awakened my being a Filipino. When I enter my classes even virtually, I always think that I am there not only as a student but also as a Filipino." PC

"While I learned to appreciate the other country's culture, the program made me appreciate more the Ilokano and Filipino culture and our country as well. I feel proud because as if I was waving the Filipino flag. " $\mathrm{PE}$

"The program affected how I see myself as a Filipino because I never thought that an ordinary student like me will represent my country as a student exchange. Deep within me, my being a Filipino in an Indonesian-filled classroom pushed me to be the best every meeting since I do not want to fail the expectations of ISPSC and my country as well." PG 


\section{Theme 4: Acquiring Digital Literary}

The narratives of the students support the argument of [23] as they admit that the encroachments of information communication technologies are the new forms of education platforms. Similarly, [24] theorized that digital network technologies can bring enormous possibilities for cooperation and knowledge generation, and sharing.

The student participants concede that emerging technologies are the new platforms for learning. Though they were seemingly pushed to go online or digital these technologies have proven their enormous potential in creating and sharing knowledge across two countriesthe Philippines and Indonesia. The new online exposure provides limitless resources but the students also developed along the way watchful eyes and critical thinking skills on deciphering legitimate from illegitimate resources.

"As I progressively became used to online platforms, I can say that I am finally comfortable with virtual learning. The new set-up had contributed to me to easily understand the lessons and participate in discussions during this new normal." PA

"With the use of online platforms and through the lectures and advice of the faculty, I learned to be more critical in choosing what I read or digest from the internet." PJ

"I learned to be more choosy on what I get as reference materials and became quite cautious with the authenticity of the materials." PD

"My exposure to online platform gave me a vast space for researching which I neglected during the old normal. I learned to use a variety of online tools especially when preparing my reports or submissions." $\mathrm{PO}$

"I am more confident now in using different apps or tools used in online learning because I learned to use them and know their strengths and limitations." $\mathrm{PB}$

\section{Theme 5: Instilling the 21st Century skills}

The acquisition of the skills needed by the students is stressed by [24] as they emphasized that online classes in the virtual international student mobility deliver to the learners extremely varied learning experiences. In this type of classroom set-up, students virtually cross the borders going to their host universities. Through the virtual exchange, students are exposed to real problem-solving contexts where collaboration with other students is an advantage and where their skills of handling the problems are put to test making the learning more meaningful [23]. This is expounded by [2] in their meta-analysis that the study abroad permeates students with profound, life-long learning effects on intercultural education and global cognizance, acquisition of foreign language, and selfdiscipline.

The internet-based collaboration provided joint actions from the students in a multi-cultural learning context. In the virtual platform, students were required to solve problems within the framework of the courses, communicate/brainstorm using the online networks, and manifest flexibility. Thus, acquiring the skills of $21 \mathrm{st}-$ century learners.

"This program creates opportunities for the participant to learn, to prosper, and to work with others and this led me to value the means of local and international collaboration, understanding, and empathy. We are able now to see differences, experience new things, and learn to appreciate the hidden skills that we never know we possess." PD

"We have the opportunity to study in a foreign nation through its virtual, mingle with a different race, and the most important is we make a way to meet in the middle." PI

"We have a lot of differences but we meet at some points where we can express ourselves in a meaningful conversation." PN

\section{CONCLUSION}

The students who participated in the International Credit Transfer Program brought home new scholarships. Through the use of the emerging information and communication technologies and online platforms as the vehicles of the teaching and learning process, the student's writing, reading, listening, and speaking competencies were honed. These competencies were recognized by the students themselves as their setbacks in the traditional classroom setup. Aside from academic enhancement, the experience taught the students to look back and reflect on being Filipinos. The students found themselves proud of their ethnicity and revived their love for their country. These thoughts served as their internal motivations to be better versions of themselves. Being able to distinguish credible sites and legitimate sources found on the internet is also one of the major take away of the participants from the program. Being analytic, critical, and cautious with what they read, watch, and share is a must for future teachers like them for these are the necessary literacies they also have to impart to their future students. Aside from being digitally literate, other 21st Century skills the students took with them as they returned home were problem-solving, communication, and flexibility. 
The virtual mobility of the exchange students is perceived as a channel that brought the students international exposure where the learning space is multilingual and culturally diverse. The virtual mobility hence is not similar to the other local/ regular online classes of the exchange students for it offered diverse, enormous, meaningful, and life-changing experiences to them.

\section{AUTHORS' CONTRIBUTIONS}

The findings of the study contributed to the creation and enhancement of existing policies related to the sustainability of the international credit transfer program which is as follows: 1 . Include in the screening criteria, the capacity, and capability of the students to have strong internet connectivity; 2. Incorporate a predeparture online seminar for the students highlighting intercultural education and communication and digital literacy; 3. Devise a monthly monitoring tool ensuring that the students maximize their learnings and stay in the host university: 4. Devise an Evaluation Sheet tailored fit for the international credit transfer program for students, teachers, and the international credit transfer program itself; and, 5. Review and revise the Primary and Secondary Education curricula anchored on the international level standards.

\section{ACKNOWLEDGMENTS}

The author would like to thank Ilocos Sur Polytechnic State College for providing funding for this endeavor. She also acknowledges the support of Dr. Gilbert R. Arce, SUC President III, Dr. Apolo S. Francisco, Vice President for Academic Affairs, Campus Administrators, Deans, Internationalization Coordinators, students, and faculty members.

\section{REFERENCES}

[1] B. T. Streitwieser, E. Le, and V. Rust, "Research on Study Abroad, Mobility, and Student Exchange in Comparative Education Scholarship," Res. Comp. Int. Educ., vol. 7, no. 1, pp. 5-19, Jan. 2012, doi: 10.2304/rcie.2012.7.1.5.

[2] T. Giedt, G. Gokcek, and J. Ghosh, "International Education in the 21st Century: The Importance of Faculty in Developing Study Abroad Research Opportunities," Front. Interdiscip. J. Study Abroad, vol. 26, pp. 167-186, Nov. 2015, doi: 10.36366/frontiers.v26i1.365.

[3] J. Knight, "Student Mobility and Internationalization: Trends and Tribulations," Res. Comp. Int. Educ., vol. 7, no. 1, pp. 20-33, Jan. 2012, doi: 10.2304/rcie.2012.7.1.20.
[4] A. Atalar, "Student Exchange: The First Step Toward International Collaboration BT Successful Global Collaborations in Higher Education Institutions," A. AI-Youbi, A. H. M. Zahed, and W. G. Tierney, Eds. Cham: Springer International Publishing, 2020, pp. 63-71.

[5] A. Mondal and J. Mete, "ICT in Higher Education: Opportunities and Challenges," 2012.

[6] L. Benade, "Is the classroom obsolete in the twenty-first century?," Educ. Philos. Theory, vol. 49, no. 8, pp. 796-807, Jul. 2017, doi: $10.1080 / 00131857.2016 .1269631$.

[7] S. Ghavifekr and H. Mahmood, "Factors affecting use of e-learning platform (SPeCTRUM) among University students in Malaysia," Educ. Inf. Technol., vol. 22, no. 1, pp. 75-100, 2017, doi: 10.1007/s10639-015-9435-z.

[8] J. M. Morse, "Evaluating Qualitative Research," Qual. Health Res., vol. 1, no. 3, pp. 283-286, Aug. 1991, doi: 10.1177/104973239100100301.

[9] M. van Manen, "Beyond assumptions: Shifting the limits of action research," Theory Pract., vol. 29, no. 3, pp. 152-157, Jun. 1990, doi: $10.1080 / 00405849009543448$.

[10] P. L. Munhall, "Revisioning phenomenology: nursing and health science research.," NLN Publ., no. 41-2545, pp. vii-xviii, 1-326, Feb. 1994.

[11] T. R. Lindlof and B. C. Taylor, Qualitative Communication Research Methods. SAGE Publications, 2002.

[12] M. Hamada, "A Facebook Project for Japanese University Students (2): Does It Really Enhance Student Interaction, Learner Autonomy, and English Abilities?," no. 2, pp. 98-105, 2013, doi: 10.14705/rpnet.2013.000145.

[13] N. Tananuraksakul, "An Investigation into the Impact of Facebook Group Usage on Students' Affect in Language Learning in a Thai Context," pp. 235-246, Jan. 2015.

[14] L. Promnitz-Hayashi, "A Learning Success Story Using Facebook," Stud. Self-Access Learn. J., pp. 309-316, Dec. 2011, doi: 10.37237/020408.

[15] S. Wichadee, "Peer feedback on facebook: The use of social networking websites to develop writing ability of undergraduate students," Turkish Online J. Distance Educ., vol. 14, no. 4, pp. 260-270, 2013, doi: 10.17718/tojde.25470.

[16] A. S. Francisco, "Read and spell: The communicative competence of english language teachers and the teaching of english as a second 
language," Asian EFL J., vol. 23, no. 3, pp. 277292, 2019.

[17] H. Ajjan and R. Hartshorne, "Investigating faculty decisions to adopt Web 2.0 technologies: Theory and empirical tests," Internet High. Educ., vol. 11, no. 2, pp. 71-80, 2008, doi: https://doi.org/10.1016/j.iheduc.2008.05.002.

[18] N. B. Ellison, C. Steinfield, and C. Lampe, "The Benefits of Facebook 'Friends:' Social Capital and College Students' Use of Online Social Network Sites," J. Comput. Commun., vol. 12, no. 4, pp. 1143-1168, Jul. 2007, doi: 10.1111/j.10836101.2007.00367.x.

[19] M. Lytras and R. García, "Semantic Web applications: A framework for industry and business exploitation - What is needed for the adoption of the Semantic Web from the market and industry," IJKL, vol. 4, pp. 93-108, Jan. 2008, doi: 10.1504/IJKL.2008.019739.

[20] L. Lomicka and G. Lord, "Social networking and language learning," Routledge Handb. Lang. Learn. Technol., no. Thorne 2010, pp. 255-268, 2016, doi: 10.4324/9781315657899.
[21] S. Thorne, "Thorne, S. L. (2010). The 'Intercultural Turn' and Language Learning in the Crucible of New Media. In F. Helm \& S. Guth (eds.), Telecollaboration 2.0 for Language and Intercultural Learning (pp. 139-164). Bern: Peter Lang.," 2010.

[22] R. Richardson and J. Munday, "International Student Mobility Programs and Effects on Student Teachers' Perceptions and Beliefs about Education and Their Role as Future Educators," Univers. J. Educ. Res., vol. 1, no. 3, pp. 240-246, 2013, doi: 10.13189/ujer.2013.010314.

[23] D. Starke-Meyerring, M. Wilson, R. Crabtree, D. Sapp, J. Malespin, and G. Norori, "Designing Globally Networked Learning Environments: Visionary Partnerships, Policies, and Pedagogies," Jan. 2008.

[24] M. Kalantzis and W. Cope, "New learning: Elements of a science of education, second edition," pp. 1-362, Jan. 2012, doi: 10.1017/CBO9781139248532. 